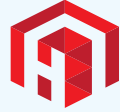 Heighten Science \\ P U B L I C A T I O N S Corporation} ISSN

2640-2866
Research Article

\section{Endovascular treatment of complex cerebral arterial saccular aneurysms with different methods of coiling: 14 years of experience review}

\author{
Dmytro V Scheglov ${ }^{1 *}$, Stanislav V Konotopchik², Maryna Y \\ Mamonova ${ }^{3}$ and Oleg E Sviridyuk ${ }^{4}$ \\ 'Interventional neurosurgeon, Director of SO "Scientific-Practical Center of endovascular \\ neuroradiology of NAMS of Ukraine", Ukraine \\ Interventional neurosurgeon, SO "Scientific-Practical Center of endovascular neuroradiology of \\ NAMS of Ukraine", Ukraine \\ ${ }^{3}$ Anesthesiologist, National Medical University n.a. O.O. Bogomolets, Ukraine \\ ${ }^{4}$ Interventional neurosurgeon, SO "Scientific-Practical Center of endovascular neuroradiology of \\ NAMS of Ukraine", Ukraine
}

*Address for Correspondence: Dr. Dmytro Shcheglov, Scientific-Practical Center of endovascular neuroradiology of NAMS of Ukraine, Email: info@neuroradiology.org.ua

Submitted: 23 March 2017

Approved: 20 June 2017

Published: 21 June 2017

Copyright: @ 2017 Scheglov DV, et al. This is an open access article distributed under the Creative Commons Attribution License, which permits unrestricted use, distribution, and reproduction in any medium, provided the original work is properly cited.

Keywords: Complexity cerebral arterial aneurysm; Aneurysm complexity criteria Endovascular occlusion; Assisting methods; Radicalism of occlusion; Recanalization

\section{SUMMARY}

The Objective: to improve the treatment results for patients with cerebral arterial saccular aneurysms by optimizing of differentiated approach to the using of endovascular assisting occlusion techniques.

Materials and Methods: The work is based on the comprehensive survey and treatment of 1345 patients with cerebral saccular arterial aneurysms (AA), who were treated at the SO "Scientific-Practical Center of endovascular neuroradiology of NAMS of Ukraine" from 2002 to 2016. 214 cases were selected for further clinicalinstrumental dynamic observation in follow-up period. All patients were operated by endovascular approach in "before hemorrhage" period, in acute or "cold" period of the disease on for symptomatic or asymptomatic intracranial saccular AA in both vascular pools with balloon-remodeling or stent-assisting techniques using with the coiling or just detachable coils (DC) using-mono-coils occlusion technique. Depending on the initial endovascular occlusion method, the patients were divided into three groups for observation: I group (monocoils occlusion)-82 (38.3\%) patients, II group (balloon-remodeling technique using)-68 (31.8\%) patients, group III (stent-assisting technique occlusion)-64 (29.9\%) patients. The life quality and the level of social adaptation were evaluated before hospital discharge and at the follow-up control examinations by Glasgow Outcome Scale (GOS) and by the modified Rankine scale (mRS). AA radicalism occlusion was assessed by Modified RaymondRoy Scale (MRRS) (Mascitelli JR, et al., 2015). AA occlusion I and II by MRRS was considered as "Effective".

Results: 9 criteria of cerebral saccular AA complexity inherent in endovascular surgery have been developed based on the technical and surgical features of endovascular methods of the cerebral AA occlusion and X-rayanatomical characteristics of aneurysms, which complicated the "effective" reconstructive occlusion of AA cavity.

The evaluation of the AA complexity criteria prognostic significance to achieve the "effective" primary occlusion, shown different results in different groups: high prognostic significance of 4 criteria was shown in group I, of 2 criteria - in group III, and no any criteria significance in group II.

There was no statistically significant difference between groups in the primary AA occlusion efficacy and initial good results by GOS and mRS.

It was proved that endovascular occlusion of complex cerebral AA with the assisting methods using has high efficiency in all periods of the disease, unlike the method of mono-coils occlusion, which is most effective in acute and "cold" periods.

There was no statistically significant difference between the number of intraoperative, postoperative and non-surgical complications ( $p>0.05)$.

It was found that all methods of complex AA endovascular occlusion can effectively prevent the disease recurrence despite the differences between them in the stability of the AA cavity occlusion.

Conclusions: Consideration of developed AA complexity criteria during endovascular surgery planning allows to choose the most optimal and safe individual method of primary or phased AA occlusion and helps to reduce the frequency of AA recanalization in follow-up period. The choice of the complex AA occlusion method doesn't effect on result of primary treatment, the number of intraoperative complications and the quality of primary occlusion. However, an analysis of the long-term treatment results indicates that the assisting techniques have proven advantages according to the occlusion stability. 
Recanalization of the AA cavity during the next 2-3 years of follow-up occurs in $42.9 \%$ of patients with mono-coils, $9.7 \%$ - with balloon-remodeling and $15.9 \%$-with stent- assistant techniques. Balloon-remodeling technique using during AA occlusion eliminates the prognostic significance of the AA complexity criteria. Stent- protection using in primary AA occlusion contributes not only to the stability of occlusion, but also to improvement of the results by angiography data in follow-up control periods in $36.4 \%$ of patients due to progressive thrombosis of the AA cavity.

Methods of cerebral AA endovascular occlusion are effective and equally safe regardless of the period of the disease. There was no statistically significant difference between groups in the effectiveness of primary occlusion and the number of perioperative complications. Good results by the GOS and mRS scales before discharge were in 77(93.9\%) patients with the mono-coils occlusion, 63(92.6\%) with balloon-remodeling and $60(93.8 \%)$ patients with the stent-assisting. Cerebral arterial aneurysm (AA) is the most frequent reason for the nontraumatic subarachnoid hemorrhage (SAH), on $50-80 \%$ caused by AA rupture $[1,2]$.

Mortality after AA rupture reached $46 \%$ during the month, almost $15 \%$ of patients die before medical care providing, about $20-30 \%$ of patients become disable as a result of persistent residual focal neurological disorders [1]. About 33\% of recurrent AA ruptures occur within 4 weeks after initial disease manifestation, about 50\%-within next 6 months and mortality from the AA re-rupture reaches $70 \%$ [1].

There are several forms of AA: saccular, fusiform and blister. The ratio of saccular AA to other AA form is 50:1 [1,3]. Saccular AA in $20-45 \%$ cases have a wide neck $(\geq 4 \mathrm{~mm}), 9-18 \%$ of cases-large and giant sizes and endovascular occlusion of these AA requires considerable effort $[4,5]$.

In endovascular surgery as in microsurgery of cerebral AA there is a term-"a complex aneurysm", which was firstly proposed by L. Hacein-Bey in 1998 [6]. Today this term is used to define a certain group of AA, which size and structure characteristic don't allow make the usual neck clipping from the standard neurosurgical approaches and require the advanced basal accesses using to get AA or a combination of microsurgical and endovascular techniques [7-9].

The definition "complex aneurysm" in AA microsurgery is clearly formulated and based on the anatomical and technical surgical characteristics of AA complexity and includes 12 criteria $[10,11]$. According to these criteria, it is believed that the part of "complex" cerebral AA is $12.7 \%-19.6 \%[11,12]$.

In modern endovascular surgery, despite of its wide using no clear defined criteria of AA complexity. At least 4 from 12 criteria from AA microsurgery are not actual for endovascular surgery, for example: hard-to-reach AA, AA with unsuccessful previous treatment, AA with calcinated walls and "AA-brain" conglomerate creating. These criteria can significantly complicate the microsurgical AA clipping but practically don't create any obstacles for endovascular AA occlusion.

\section{OBJECTIVE}

To improve the treatment results for patients with cerebral arterial saccular aneurysms by optimizing of differentiated approach to the using of endovascular assisting occlusion techniques.

\section{MATERIALS AND METHODS}

The work is based on the comprehensive survey and treatment of 1345 patients with cerebral saccular arterial aneurysms (AA), who were treated at the SO "ScientificPractical Center of endovascular neuroradiology of NAMS of Ukraine" from 2002 to 2016. 214 cases were selected for further clinical-instrumental dynamic observation in follow-up period. 


\section{Inclusion criteria}

patients were operated by endovascular approach in "before hemorrhage" period, in acute or "cold" period of the disease on for symptomatic or asymptomatic intracranial saccular AA in both vascular pools with balloon-remodeling or stentassisting techniques using together with the coiling or just detachable coils (DC) usingmono-coils occlusion technique, irrespective of the size, which had one or more of the criteria listed below:

1. AA with a wide neck (ratio of AA dome width-AA neck width $<2$ or neck width $\geq 4 \mathrm{~mm}$ )

2. Bifurcation or side AA, which neck diameter $\geq$ bearing artery diametr

3. Side AA, which have branch artery in the neck area

4. AA with complex geometry, which have branch artery in the dome area

5. AA with complex shape of the dome

6. Multi-chamber AA

7. AA located at an acute angle to the bearing artery

8. Partially thrombosed AA

\section{Exclusion criteria}

1. Multiple AA

2. AA of head and neck main arteries with extracranial location.

3. Fusiform AA

4. Complex AA, operated by endovascular approach with the extra-saccular technique using for AA exclusion from bloodstream (Flow-Diverter Stent).

5. Complex AA, operated by endovascular approach with detachable balloons using.

6. Complex AA, operated by endovascular planned deconstruction technique.

7. Patients with degree of severity-V by Hunt-Hess and WFNS scales during the initial hospitalization.

Depend on initial occlusion method, patients were divided into three groups for observation: I group (mono-coil socclusion)-82 (38.3\%) patients, II group (balloonremodeling technique using)-68 (31.8\%) patients, group III (stent-assisting technique using)-64 (29.9\%) patients. The choice of the AA primary occlusion method was conditioned by the disease period, the presence and severity of angiospasm, structural and angio-architectonic aneurysm features and the availability of the necessary endovascular instrumentation.

Groups were comparable by age and sex composition, the severity of the clinical condition in the acute period of hemorrhage and aneurysm angiographic characteristics ( $p>0.05)$. The patients gender istribution in groups is shown in table 1.

The patient distribution in groups by the age (according to the WHO classification (1963)) is presented in table 2. The age was between 14 and 76 years. In all groups, younger and middle-aged patients predominated: group I (90.2\%), group II (86.8\%), group III (70.3\%). 
The severity of the clinical condition during primary hospitalization was assessed according to the Hunt-Hess scale (Hunt W, Hess R, 1968) and WFNS (World Federation of Neurosurgical Societies scale, 1988). It was found that the difference between groups in the acute period of the disease was not statistically significant ( $\mathrm{p}=0.456$ ). In all cases, patients with grade II and III prevailed, it was about $78.6 \%$ of the total number of patients in the acute period of the disease. AA localization is presented in table 3.

AA were distributed by size according D.V. Shchehlov classification (2014): up to $3 \mathrm{~mm}$ (micro aneurysms), $4-5 \mathrm{~mm}$ (small), $6-10 \mathrm{~mm}$ and $11-15 \mathrm{~mm}$ (middle), $16-$ $20 \mathrm{~mm}$ (large), more than $20 \mathrm{~mm}$ (giant). During the aneurysm size calculating the basic parameter was the aneurysmal greatest length and in the case of multi-cavity aneurysm - the greatest lengths of all cavities. During the calculation of the parameter "ratio of the dome to neck" the width of the AA was taken as the main size of the dome. And in cases of multi-cavity AA - the width of its initial cavity.

Small and middle AA (4-15 $\mathrm{mm}$ ) were prevailed in all groups - $81.3 \%$ from the total number of AA. At the same time, AA with size $6-10 \mathrm{~mm}$ accounted for $44.4 \%$ of cases and prevailed in groups I and III. Microaneurysms prevailed in group II, and there were no giant AA in groups II and III. This is due to the fact that giant AAs last years operated by extrasaccular technique of AA exlusion from the blood stream (FD-stents using). The life quality and the level of social adaptation were evaluated before hospital discharge

\begin{tabular}{|c|c|c|c|c|c|c|c|c|}
\hline \multirow{2}{*}{ Gender } & \multicolumn{2}{|c|}{ I group } & \multicolumn{2}{|c|}{ II group } & \multicolumn{2}{|c|}{ III group } & \multicolumn{2}{|c|}{ Totally } \\
\hline & Abs.\# & $\%$ & Abs.\# & $\%$ & Abs.\# & $\%$ & Abs.\# & $\%$ \\
\hline Male & 37 & 45,1 & 33 & 48,5 & 27 & 42,2 & 97 & 45,3 \\
\hline Female & 45 & 54,9 & 35 & 51,5 & 37 & 57,8 & 117 & 54,7 \\
\hline Totally & 82 & 100 & 68 & 100 & 64 & 100 & 214 & 100 \\
\hline$P\left(x^{2}\right)$ & \multicolumn{6}{|c|}{$p=0,764^{*}$} & & \\
\hline
\end{tabular}

Note: $P(x 2)$ - is an estimate of the probability of the difference between groups according to the criterion $\mathrm{X}^{2} ;{ }^{*}$ - the difference is statistically insignificant.

Table 2: Patients distribution by the age.

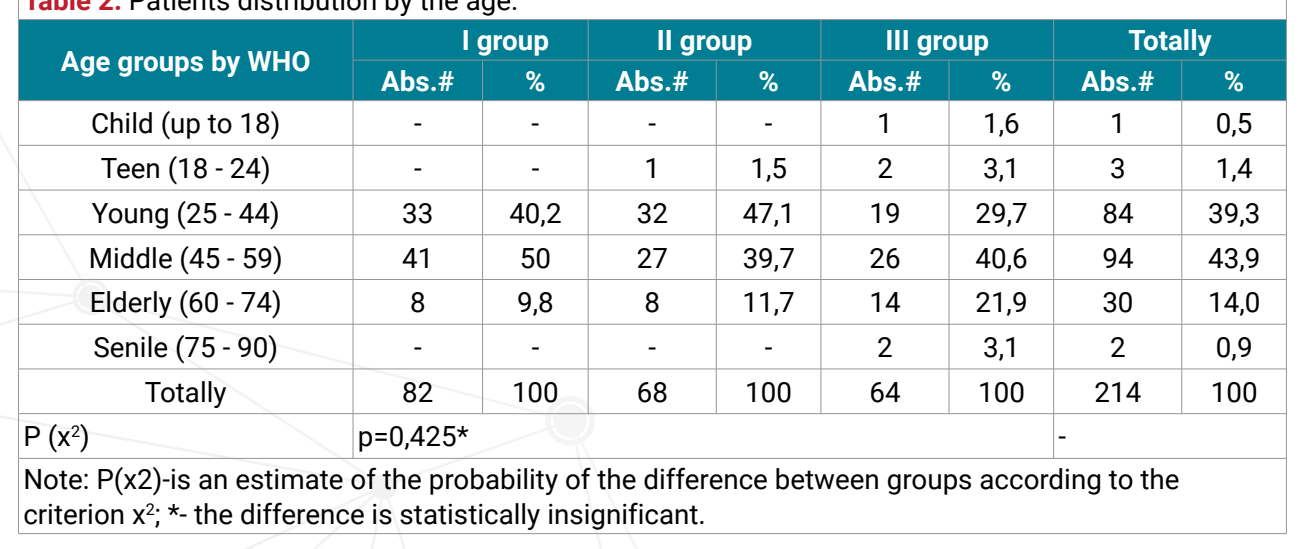

\begin{tabular}{|c|c|c|c|c|c|c|c|c|}
\hline \multirow{3}{*}{ Localization } & \multicolumn{8}{|c|}{ Number of observations } \\
\hline & \multicolumn{2}{|r|}{ I group } & \multicolumn{2}{|c|}{ II group } & \multicolumn{2}{|c|}{ III group } & \multicolumn{2}{|c|}{ Totally } \\
\hline & $\%$ & Abs.\# & $\%$ & Abs.\# & $\%$ & Abs.\# & $\%$ & Abs.\# \\
\hline Internal Carotid Artery & 31 & 37,8 & 35 & 51,5 & 28 & 43,8 & 94 & 43,9 \\
\hline Middle Cerebral Artery & 17 & 20,7 & 15 & 22 & 14 & 21,9 & 46 & 21,5 \\
\hline $\begin{array}{c}\text { Anterior Cerebral - Anterior Communicating } \\
\text { Artery }\end{array}$ & 19 & 23,2 & 17 & 25 & 7 & 10,9 & 43 & 20,1 \\
\hline Vertebro-Basilar pool & 15 & 18,3 & 1 & 1,5 & 15 & 23,4 & 31 & 14,5 \\
\hline Totally & 82 & 100 & 68 & 100 & 64 & 100 & 214 & 100 \\
\hline
\end{tabular}


and at the follow-up control examinations by Glasgow Outcome Scale (GOS) and by the modified Rankine scale (mRS).

Complications and their predictors (risk factors) that occurred in patients during treatment period were evaluated according to the classification of predictors/ complications of endovascular treatment in patients with cerebral AA, proposed by D.V. Shchehlov [4]. Dynamic instrumental observations carried out in early (30 days) and long follow-up (3-6 months, 1 year, 2-3 years, 4-5 years, over 5 years) postoperative periods. AA radicalism occlusion was assessed by Modified Raymond - Roy Scale (MRRS) (Mascitelli JR, et al., 2015). AA occlusion I and II by MRRS was considered as "Effective".

Next points were assessed in the early (30 days) postoperative period: degree of the primary AA occlusion, functional changes in patients after treatment, their level of social adaptation, the nature, prevalence and severity of complications (if any) based on the clinical observation, instrumental methods data: Cerebral Angiography (CA), Multispiral Computed Tomography and Multispiral Computed Tomography with Angioprogram (MCT/MCT-AG), Magnetic Resonance Imaging and Magnetic Resonance Imaging with Angioprogram (MRI/MRI-AG).

Next criteria were evaluated in the long follow-up periods: AA occlusion radicalism, dynamic of AA occlusion degree, complications. The dynamics of patient neurological status after treatment was analyzed separately: the level of social adaptation, quality of life and ability to work, because the neurological status didn't always converge with the degree of endovascular AA occlusion.

Given the fact that most of the data for statistical Annalise is the qualitative characteristics, we used criteria chi-squared test $(\chi 2)$ to assess the statistical significance of the difference between groups. In cases with small number of observations (less than 5), we used accurate Fisher criteria. For comparison of average values we used Mann-Whitney $U$ test and T-criteria with a preliminary assessment of the nature of the distribution of initial data (estimation of the normal distribution) by Shapiro-Wilk test. Confidence intervals were within $95 \%$, differences in indicators were considered reliable with the probability of the validity of the null hypothesis less than $5 \%(\mathrm{p}<0.05)$.

\section{RESULTS}

9 criteria of cerebral saccular AA complexity inherent in endovascular surgery have been developed based on the technical and surgical features of endovascular methods of the cerebral AA occlusion and X-ray-anatomical characteristics of aneurysms, which complicated the "effective" reconstructive occlusion of AA cavity in 1345 patients.

\section{Surgical complexity criteria}

The angle of slope of AA dome relative to the proximal segment of the bearing artery $<90^{\circ}$ (Figure 1 ).

Branch arteries in the neck area or AA dome (Figure 2,3).

\section{X-ray-anatomical complexity criteria}

1. Width of AA neck $\geq 4 \mathrm{~mm}$ (Figure 4)

2. The ratio of the neck width to the AA dome width $<2$ (Figure 5)

3. The ratio of the neck width to the bearing artery diameter (neck $\geq$ artery diameter) (Figure 6, 7)

4. A complex form of the AA dome (Figure 8, 9)

5. Multi- chamber AA (Figure 9) 
6. Large and giant AA (Figure 10)

\section{Partially thrombosed AA}

It was found that the proportion of complex AA in the structures of cerebral saccular AA is $17.4 \%$. When AA is located at an acute angle to the proximal segment to the bearing artery, it is difficult to achieve a stable position of the microcatheter in AA cavity during occlusion, therefore such operations require the protective techniques using (Figure 1).

During the endovascular operations on side AA, which have branch artery in the neck area such important to achieve maximal full cavity occlusion and to safe the patency of artery in the neck area. On our opinion-it possible with mono-coils technique or "semi-jailing" technique (stent or balloon) using, which allow to control as closely as possible the coiling in the area of AA neck (Figure 2).

Occlusion of AA with complex geometry, which have branch artery in the dome area - I's the most difficult target, because it requires to safe this artery during coiling
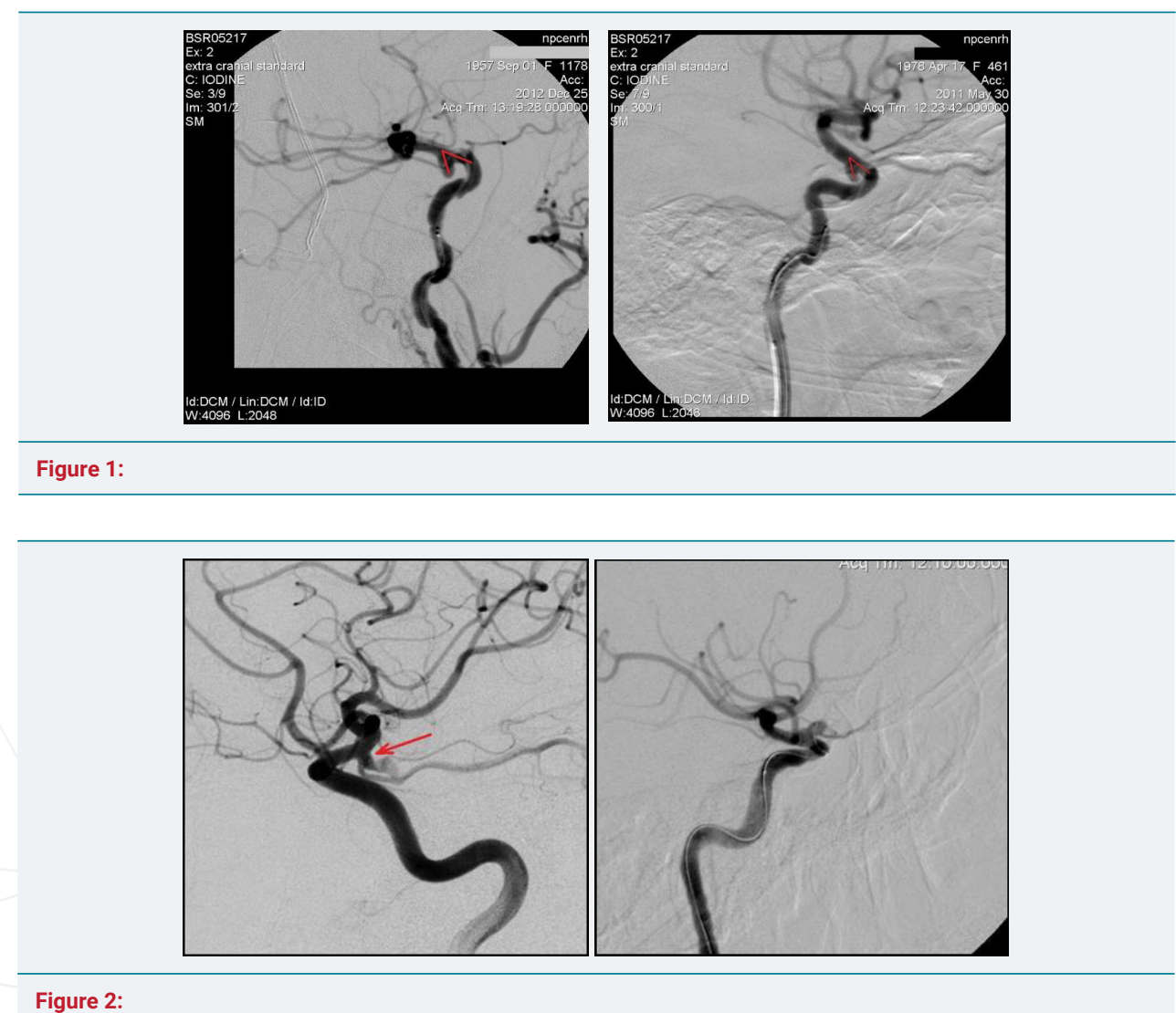

Figure 2:

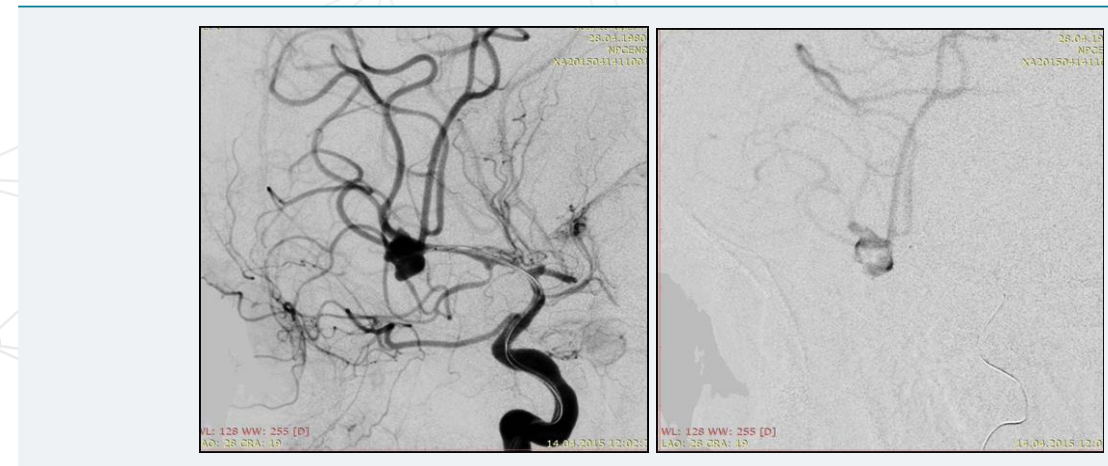

Figure 3: 
and to achieve the maxi filling density. That is very important for symptom AA. In most of these cases we used mono-coils technique (Figure 3).

In AA surgery the wide neck $\geq 4 \mathrm{~mm}$-it's probably the main parameter by which most scientists attribute AA to the complex. Mono-coiling of such AA entails significant risks (coil prolapse, coil migration and occlusion of the bearing artery). AA with neck $\geq 4 \mathrm{~mm}$ have a high percentage of recanalization. According to J. Raymond in AA with wide nec $\geq 4 \mathrm{~mm}$ the recanalization frequency increases in 4 times compared to AA which narrow neck [13]. In these cases balloon and stent-assisting techniques should be used to protect bearing artery from coils prolapse in its lumen (Figure 4).

AA with a wide neck when the ratio of AA dome width-AA neck width $<2 \mathrm{~mm}$ another, most common in the literature complexity criteria. On our opinion it's more correct as complexity criteria for AA with size less than $15 \mathrm{~mm}$ than the previous one (Figure 5).

The ratio of the neck width to the bearing artery diameter (neck $\geq$ artery diameter)this criteria becomes especially important in angiospasm of bearing artery. During the occlusion the neck width can notably exceed the bearing artery diameter, forcing surgeons to conduct less dense fill AA within this region. Further, in period of angiospasm regression, a change occurs in this relation, what, on our opinion is one of the reasons of AA recanalization, operated in the acute period of SAH (Figure 6).

Mono-coils method in AA with neck $\geq$ artery diameter practically impossible, because of high rick of prolapse DC in to bearing artery lumen. Such AA require stentassisting (more often) or balloon-assisting techniques.

Bifurcation AA occlusion, when the neck $\geq$ artery diameter absolutely possible not only with assisting techniques using, because the axial blood flow directs to the tip of the bifurcation, which causes hemodynamic pressure on this region and helps to keep coils in AA cavity (Figure 7).
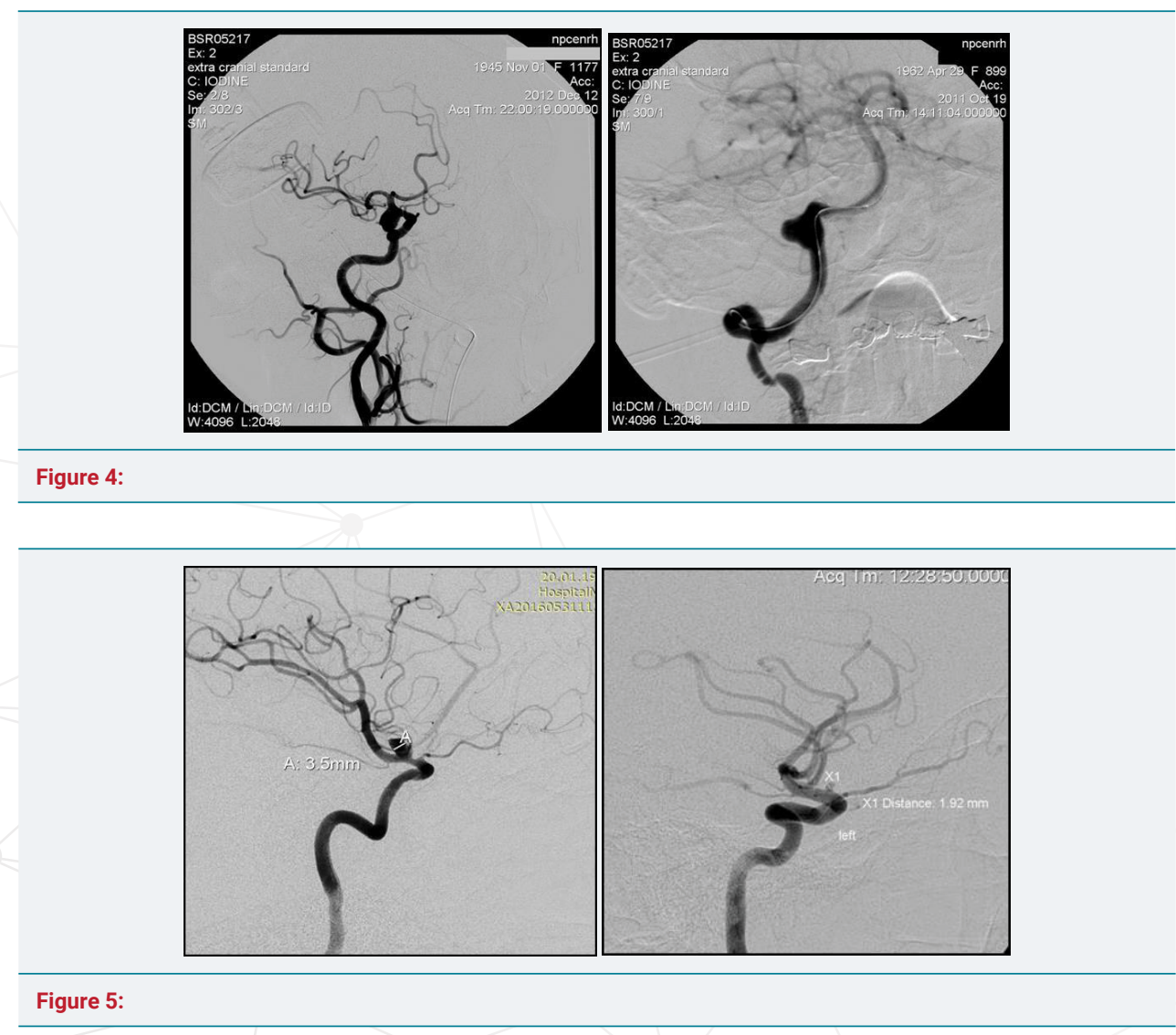
Supporting by micro catheter is more pronounced in such cases, than during coiling of side AA and the using of DC with 3D-form gives the ability to make AA occlusion, without assisting techniques. The complex form of the initial coil makes it possible to reliably place it in the complex AA cavity and prevent subsequent its migration.

The complex form and multi-chambering of AA are the X-ray-anatomic criteria of AA complexity. Complex form of AA doesn't allow to achieve a good and, most importantly, uniform coils fitting over the entire area of the AA walls, as a result of which the density of occlusion becomes also irregular (more-in the center and less-in the area of AA dome), which often prevents achieving total primary AA occlusion.

Furthermore, the above-mentioned features of coils disposition near AA walls, we believe, can become predictors of recanalization of the AA cavity due to more pronounced compaction and "subsidence" of their conglomerate in the AA dome bend and diverticulum.

The situation become more difficult in case of multi-chamber AA, especially in multi-chamber AA with complex form. In such cases it's difficult to achieve the uniform density of DC conglomerate in AA cavity, sometimes it can be dangerous for patient, because the compact coiling in distal chamber, which often has diverticulum (rupture place), carries, in our opinion, a high risk of intraoperative rupture.

Different bends of AA dome are inherent for single-chamber AA with complex form (Figure 8). Multi-chamber AA are complex, if chambers have different size and form, uneven contours and located one in relation to the other at different angles (Figure 9).Large and giant AAs, as rule, have several complexity criteria in the same time, because of their size. In the same reason, it's practically impossible to achieve the high coil density. Firstly, it requires a huge amount of DC, what significantly increases the operation price. Secondly, such AAs in themselves by their size have a volumentic effect on the surrounding structures, furthermore, the dense cavity tamponade may increases this effect and enhances the neurological deficit.
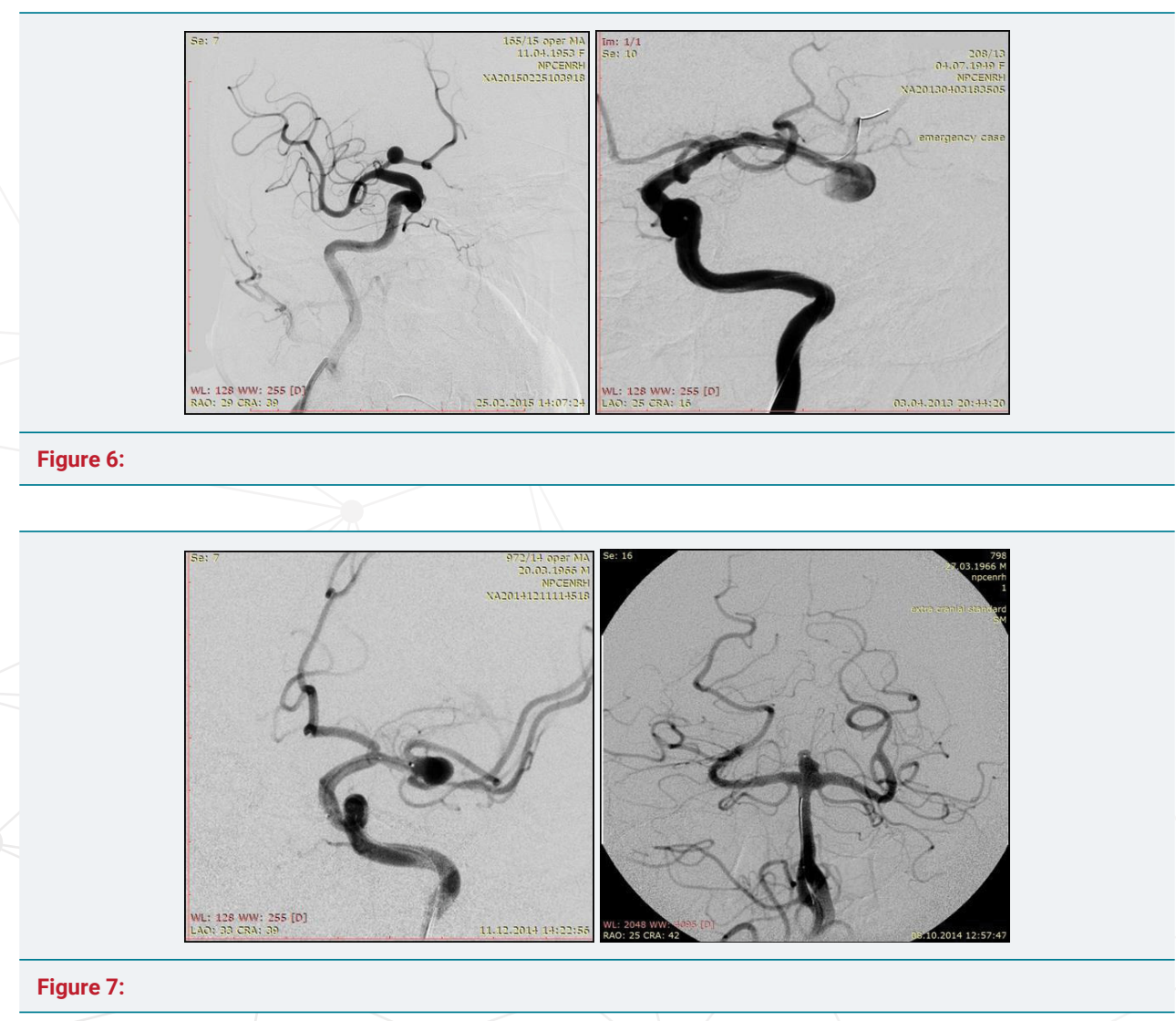
That is why today these AA exclusion from circulation performed, if possible, with using of flow - diverter devices through the planned reconstruction, or by combination of microsurgical and endovascular techniques (Figure 10). Partially thrombosed AA: thrombus form under conditions of considerable turbulence or if epy blood stasis occurs in the AA cavity $[14,15]$. Perhaps, thrombus weakens pressure fluctuations and reduces its impact on the AA wall and reduces the risk of endothelial damage, however, thrombus inside AA-is one of the main causes of high recanalization frequency (Figure
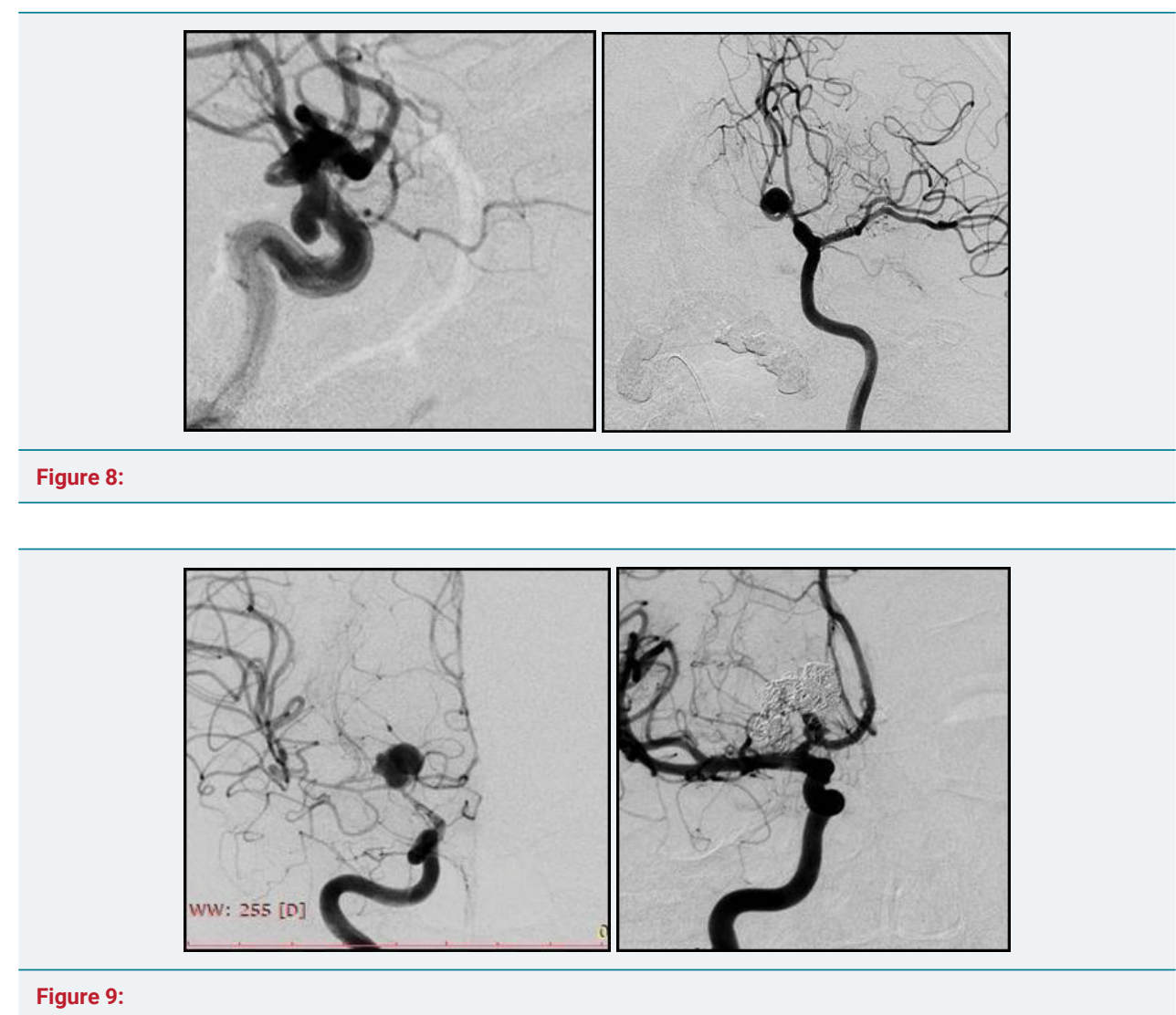

Figure 9:

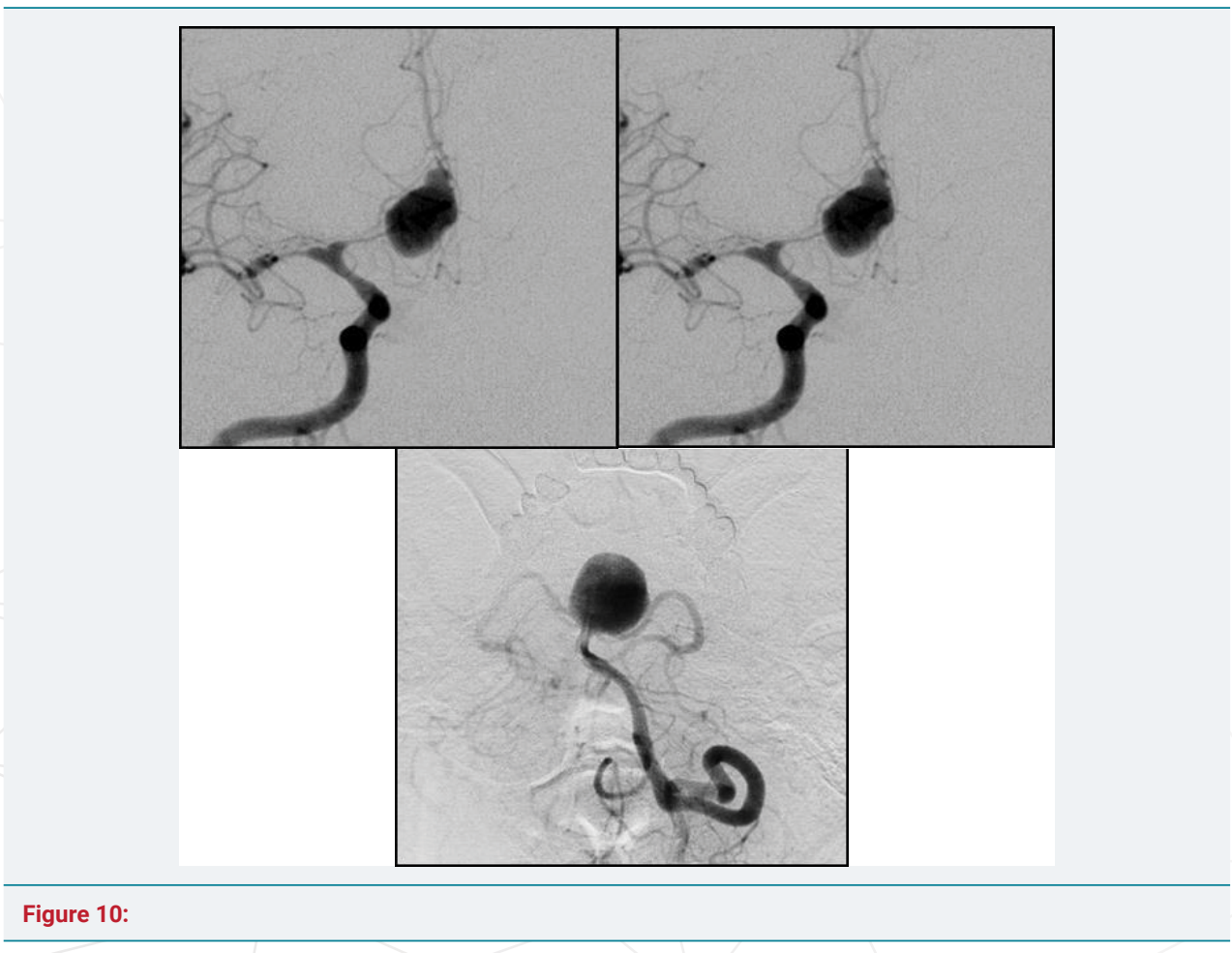


11). The evaluation of the AA complexity criteria prognostic significance to achieve the "effective" primary occlusion, shown different results in different groups: high prognostic significance of 4 criteria was shown in group I (mono-coilsocclusion): width of AA neck, the ratio of the neck width to the bearing artery diameter, the ratio of the AA dome width to the neck width, complexity of AA dome.

Balloon-assissting technique using during AA occlusion by coils excluded the prognostic significance of all criteria of the AA complexity in achieving an effective primary occlusion-group II.

In group III (stent-assisting) we found 2 prognostically significant criteria of AA complexity: width of AA neck, the ratio of the neck width to the bearing artery diameter. The highest level of "effective" initial occlusion was observed in group I групі (Raymond I and II) after coiling in ruptured AA (in "cold" period-92.3\%, in acute period-80\%), the lowest-after endovascular AA occlusion in pre-hemorrhage period $57.9 \%$.

The highest rate of "effective" initial occlusion was observed in group II after AA coiling in "cold" period-84.6\% $(\mathrm{n}=11)$ and the lowest in pre-hemorrhage period $76 \%$ and acute period- $70 \%(\mathrm{n}=21)$.

In group III-the rate of "effective" initial occlusion in pre-hemorrhage period-71.9\% $(\mathrm{n}=23)$ and almost identical in "cold" and acute periods-64.3\% ( $\mathrm{n}=9)$ Thus, the endovascular coils occlusion of complex AA using assisting techniques is highly effective in all periods of the disease, in contrast to mono-coils occlusion, which is most effective in acute and "cold" periods of the disease.

Good results by GOS before discharge were observed in 77 (93.9\%) patients from group I, 63 (92.6 \%)-in group II and 60 (93.8\%)-in group III. The difference between the groups in this indicator was statistically insignificant $(p>0.05)$. Characteristics of complications (related and unrelated to the operation) or their predictors that occurred

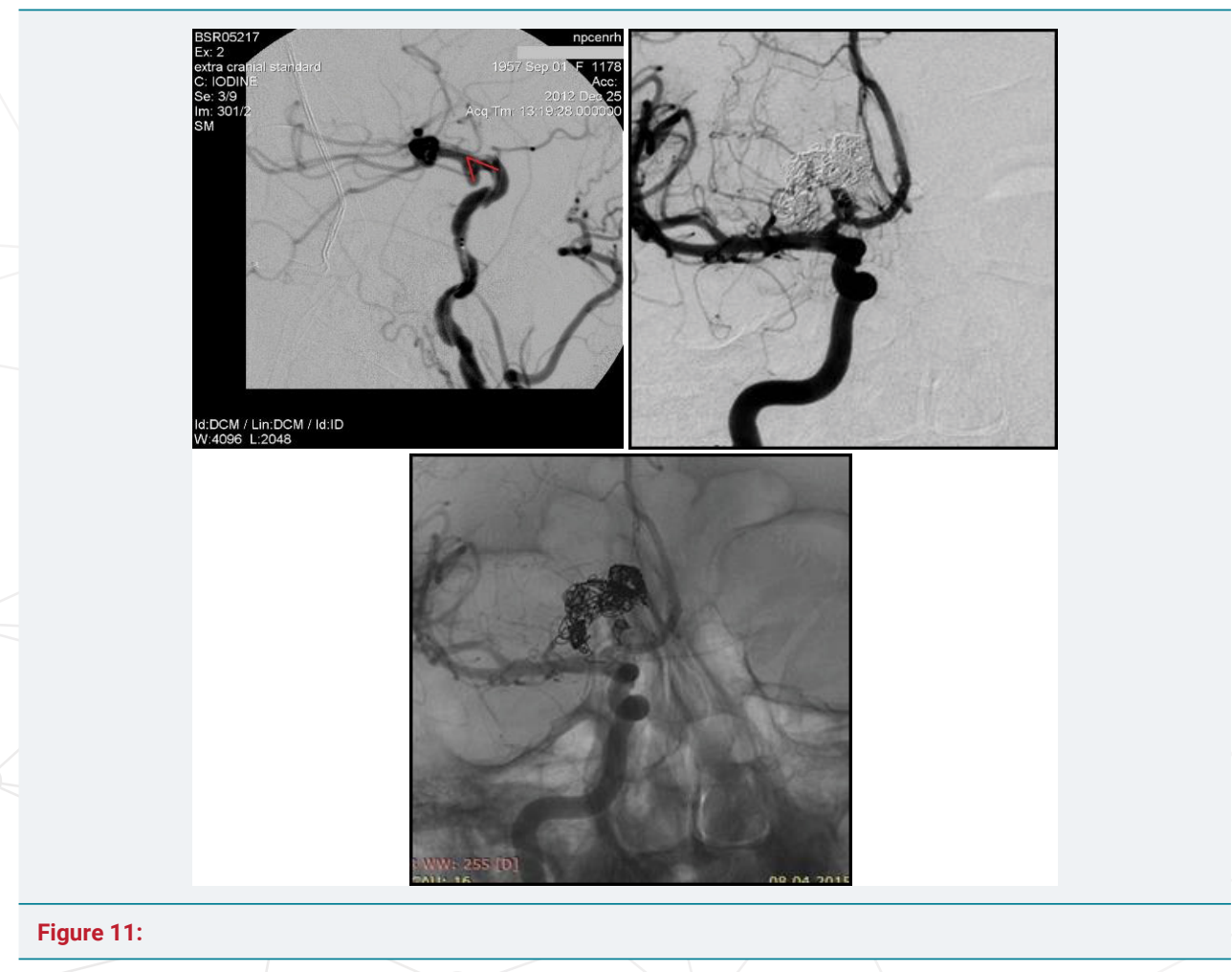


in patients intraoperatively or in the early follow-up period, as well as the dynamics of their clinical manifestations is presented in table 4. We also didn't find statistically significant difference between the groups in the number of intra-postoperative or nonoperative complications ( $\mathrm{p}>0.05)$.

As a result of the study, there was no statistically significant difference between the groups in a percentage of "effective" primary AA occlusion ( $p>0.05)$. The "effective" occlusion in group I was reached in 63 (76.8\%) cases, in gropu II-in 51 (75\%) and in group III-in 44 (68.7\%) cases. Long-term treatment results in group I were evaluated in $70(89.7 \%)$ from the possible 78 cases, in group II-in 41 (64.1\%) from the possible 64 , in group III-in 44 (75.9\%), from the possible 58.

In patients of group I during 2-3 years of observation, occlusion was effective or remained stable in $34(48.5 \%)$ cases. Deterioration of the results by AG data

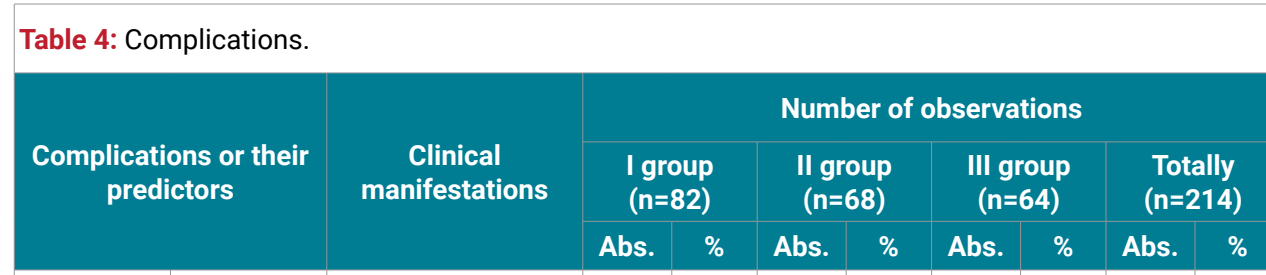

\begin{tabular}{|c|c|c|c|c|c|c|c|c|c|c|}
\hline \multirow{8}{*}{ 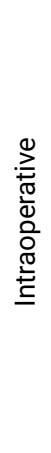 } & \multirow{4}{*}{ 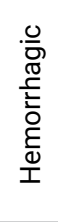 } & no symptoms & - & - & - & - & - & - & - & - \\
\hline & & passing & 2 & 2,4 & 1 & 1,5 & - & - & 3 & 1,4 \\
\hline & & persistent & - & - & - & - & 1 & 1,6 & 1 & 0,5 \\
\hline & & death & - & - & 1 & 1,5 & - & - & 1 & 0,5 \\
\hline & \multirow{4}{*}{$\begin{array}{l}\frac{0}{E} \\
\frac{\delta}{d} \\
\frac{\tilde{D}}{0} \\
\underline{\omega}\end{array}$} & no symptoms & 4 & 4,9 & 6 & 8,7 & 2 & 3,1 & 12 & 5,6 \\
\hline & & passing & - & - & 1 & 1,5 & 2 & 3,1 & 3 & 1,4 \\
\hline & & persistent & 1 & 1,2 & 1 & 1,5 & 1 & 1,6 & 3 & 1,4 \\
\hline & & death & - & - & - & - & - & - & - & - \\
\hline \multicolumn{3}{|c|}{$P\left(x^{2}\right)$ - intra-operative } & \multicolumn{6}{|c|}{$P=0,615^{\star}$} & - & - \\
\hline \multirow{8}{*}{$\begin{array}{l}0 \\
\stackrel{0}{ \pm} \\
\frac{\pi}{0} \\
0 \\
0 \\
0 \\
\frac{1}{0} \\
0 \\
0\end{array}$} & \multirow{4}{*}{ 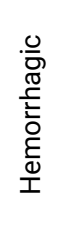 } & no symptoms & - & - & - & - & - & - & - & - \\
\hline & & passing & - & - & - & - & - & - & - & - \\
\hline & & persistent & - & - & - & - & - & - & - & - \\
\hline & & death & 1 & 1,2 & - & - & 1 & 1,6 & 2 & 0,9 \\
\hline & \multirow{4}{*}{$\begin{array}{l}\frac{0}{E} \\
\frac{0}{d} \\
\underline{\varrho} \\
\underline{\varrho}\end{array}$} & no symptoms & - & - & - & - & - & - & - & - \\
\hline & & passing & - & - & 1 & 1,5 & 3 & 4,6 & 4 & 1,8 \\
\hline & & persistent & 1 & 1,2 & - & - & - & - & 1 & 0,5 \\
\hline & & death & - & - & - & - & - & - & - & - \\
\hline \multicolumn{3}{|c|}{$P\left(x^{2}\right)$ - post-operative } & \multicolumn{6}{|c|}{$P=0,263^{*}$} & - & - \\
\hline \multirow{3}{*}{\multicolumn{2}{|c|}{$\begin{array}{l}\text { unrelated to the } \\
\text { operation }\end{array}$}} & passing & 5 & 6,2 & - & - & 2 & 3,1 & 7 & 3,3 \\
\hline & & persistent & 2 & 2,4 & 3 & 4,4 & 2 & 3,1 & 7 & 3,3 \\
\hline & & death & 2 & 2,4 & - & - & 1 & 1,6 & 3 & 1,4 \\
\hline \multicolumn{3}{|c|}{$P\left(x^{2}\right)$ - unrelated to the operation } & \multicolumn{6}{|c|}{$P=0,334$} & - & - \\
\hline \multicolumn{3}{|c|}{ Totally } & 18 & 21,9 & 14 & 20,6 & 15 & 23,4 & 47 & 22,0 \\
\hline \multicolumn{3}{|c|}{$\mathrm{P}\left(\mathrm{x}^{2}\right)$ - Разом } & \multicolumn{6}{|c|}{$P=0,925^{\star}$} & - & - \\
\hline
\end{tabular}

Note: $\mathrm{P}(\mathrm{x} 2)$ - is an estimate of the probability of the difference between groups according to the criterion $\mathrm{x}^{2}$;

*- the difference is statistically insignificant 
(recanalization of the AA cavity) was noted in 30 (42.9\%) patients: 20 (28.6\%) during the first 3-6 months after operation, 9 (12.9\%) - after 1 year and in $1(1.4 \%)$ patientafter 3 years. Improvement in the results by AG data (a higher degree of AA occlusion in comparison with the primary operation) was observed in $6(8.6 \%)$ patients in the first 3-6 months. Thus, good results (stable occlusion or its improvement) are achieved in $40(57.1 \%)$ observations. The condition of all 70 patients was evaluated in 5 points by GOS in period from 3 months to 3 years after initial operation; by mRS the condition of $62(88.6 \%)$ patients was 0 points and in $8(11.4 \%)$ patients- 1 point.

In patients of group II in follow-up period 2-3 years, occlusion was effective or remained stable in 27 (65.9\%) cases. Deterioration of the results by AG data occurred in $4(9.7 \%)$ patients, and improvement in $10(24.4 \%)$. Thus, good results were achieved in $37(90.3 \%)$ cases. $40(97.6 \%)$ patients had 5 points by GOS in the period 3 months 3 years after initial occlusion, and in $1(2.4 \%)$ patient by 3 points (the same with the early postoperative period); by mRS 38 (92.7\%) patients had 0 points, 2 (4.9\%)-1 point, $1(2.4 \%)-4$ points (before the discharge after initial operation the same).

In Group III, during 2-3 years follow-up, occlusion was effective or remained stable in $21(47.7 \%)$ observations. Deterioration of the results by AG data was noted in 7 (15.9\%) patients, and improvement in 16 (36.4\%). Thus, good results were achieved in $37(84.1 \%)$ patients. 42 (95.5\%) patients in period 3 months- 3 years had 5 ponts by GOS, $2(4,5 \%)$ patinets-4 points; by mRS $40(90.9 \%)$ cases-0 points, 3 (6.8\%) cases-1 point, $1(2.3 \%)$ case-2 points (the same with early postoperative).

In group I, recanalization observed more significantly canalization among AA: operated in the cold period, large and giant AA, with the degree of primary occlusion II-IIIa by mRS, with thrombus in the AA cavity, with branch arteries in the neck or dome area, in multi-chamber AA, with the ratio of the neck to the AA dome width $<2$ (due to large and giant $\mathrm{AA}$ ).

In group II, a statistically significant amount of recanalization was noted in AA with the degree of primary occlusion III by mRS. In group III- in AA with a thrombus in the AA cavity and in large AA.

Due to the recanalization of AA, in group 1, 45 repeated occlusions were performed in 31 patients, in group II- only 6 repeated operations in 5 patients and in group III - 6 operations in 4 patients.

Gropu I had 45 peoperations, jusdt in 4 (8.9\%) cases we observed complications related to the operation: 2 (4.4\%) during stent-assisting, 1 (2.2\%) during ballonremodelling and $1(2.2 \%)$ - during mono-coils occlusion. Intraoperative complications occurred in $3(6.7 \%)$ cases (by one for each group) resulted in to brain ischemia: 2 (4.4\%) passing, $1(2.2 \%)$ without symptoms. In group II-were no any complications during reoperations.

In group III- 6 reoperations and only 1 brain ischemia without symptoms during mono-coils operation violation of the pericentral branch of the Middle Cerebral Artery. We found that all methods of complex AA endovascular occlusion can effectively prevent the disease recurrence, despite the difference in the stability of the AA cavity occlusion, since only $1(1.4 \%)$ patient in group I and $1(2.3 \%)$ patient in group III had intracranial hemorrhage due to rupture of AA in the long-term follow-up period.

\section{DISCUSSION}

Since the publication of the first experience of coil using in humans to occlude AA from the bloodstream, the intention to improve the efficiency of endovascular AA surgery and to expand its capabilities has appeared [16]. Further rapid development of interventional neuroradiology, improvement of the coils and delivery catheters 
design, introduction of non-standard mono-coils techniques for AA occlusion made it possible to obtain a high density of filling by coils and maintaining the stability of their conglomerate in the simple AA cavity. However, the occlusion of complex AA remains a difficult task for mono-coils technique.

It is inspired scientists to develop assisting techniques, and already in the mid1990 s, two methods of supporting traditional AA occlusion with a balloon catheter and, later, with a protective stent, were proposed. The technique of balloon-assisting, or balloon-remodeling technique, with the endovascular coil occlusion of AA with complex dome geometry and wide neck was first described by J. Moret [17]. This idea of balloon-assisting using for AA occlusion was not new. Long before the DC development, a technique with assisting balloon using "balloon-cattleman" during AA occlusion by silicone balloons was proposed by V.I. Shchehlov (Research Institute of Neurosurgery named after AP Romodanov, Kiev, Ukraine) [18-20]. Shchehlov's tandem - the technique of supporting the detachable balloon by adjuvant non-detachable "balloon-cattleman", well proved itself in the future and developed in combination with coils leter $[21,22]$.

Analysis of literature data and scientific papers on different aspects of the monocoils, balloon-remodeling and stent-assisted methods of cerebral AA endovascular occlusion made it possible to draw conclusions about the insufficient investigations of some questions: about the comparative analysis of their effectiveness and the absence of clearly defined criteria for the complexity of cerebral AA inherent in endovascular surgery. It complicates the development of individualized surgical tactics in primary or reoperations.

The development of endovascular X-ray-anatomical and surgical criteria for the AA complexity, the study of their effect on the efficiency of the AA cavity primary occlusion and the dynamics of occlusion quality in follow-up periods, the study of complications with different methods of AA exclusion from the blood stream are urgent problems of modern endovascular surgery. The possibility of improving the treatment results for this patient's category depends on these aspects.

We think that the tactics of the endovascular operation should be determined based on selective cerebral angiography and non-invasive methods of neuroimaging, taking into account the developed criteria for the AA complexity and the period of the disease. Priority should be given to assisting technicians during the complex AAs exclusion from the blood stream. It's especially important in the presence of such complexity surgical criteria - the inclination angle of the AA dome to the proximal segment of the supporting artery $<90$.

Summarizing the data obtained, namely, a differentiated approach to the various assisting techniques using based on the AA complexity criteria, and it achieves an effective stable AA cavity occlusion, minimizes intraoperative complications, prevents recurrence of the disease and provides a positive clinical outcome while maintaining a high life quality for the patient.

\section{CONCLUSIONS}

Accounting developed criteria for the AA complexity during the planning of the endovascular operation allows us to make reasonably choose of the optimal and safest method of primary or stage-by-stage AA occlusion, individualize the operative tactic and reduce the frequency of recanalization.

The choice of the AA exclusion method doesn't effect on the result of primary treatment, the number of intraoperative complications and the quality of primary occlusion, however, the analysis of long-term results indicates that the assisting techniques have an evident advantage in relation to occlusion stability. AA cavity recanalization over the next 2-3 years occurred in $42.9 \%$ of patients with mono-coils technique, in $9.7 \%$ with balloon-remodeling and in $15.9 \%$ with the stent-assisting. 
Balloon-remodeling technique using during AA cavity coil filling excludes the prognostic significance of all the criteria for the complex AA to achieve effective primary occlusion. Protective stent using during primary coiling promotes not only the occlusion stability, but also the improvement of results in late follow-up periods based on control AG data in $36,4 \%$ of patients during control examinations due to the progressive AA cavity thrombosis.

Endovascular methods of AA exclusion are effective and are equally safe independently on disease period. No found any statistically significant difference between groups in the effectiveness of primary occlusion and the number of perioperative complications. Good results by the GOS and mRS scales before discharge were in 77 (93.9\%) patients with the mono-coils occlusion, 63 (92.6\%) with balloonremodeling and 60 (93.8\%) patients with the stent-assisting.

\section{REFERENCES}

1. Krylov VV, Godkov DV. Cerebral aneurysm surgery. Editor Krylov VV, Moscow, Novoe Vremya. 2011; 1: $12-15$.

2. Choudhri $\mathrm{O}$, Mukerji N. Combined endovascular and microsurgical management of complex cerebral aneurysms. Front Neurol. 2013; 4: 108-115. Ref.: https://goo.gl/T1xHdR

3. Byrne JV, Guglielmi G. Endovascular treatment of intracranial aneurysms. 1998; 248. Ref.: https://goo.gl/6c16Yc

4. Shchehlov DV. Diagnostics and endovascular treatment of intracranial arterial aneurysms: author's abstract. Dis. For Dr. Med. Sciences. Neurosurgery, Kyiv, 2014; 13-27.

5. Kandyba DV, Babichev KN, Savello AV. The role of assisting methods for intravascular occlusion of cerebral aneurysm. Circul Pathol Cardiac Surg. 2012; 3: 27-34.

6. Hacein-Bey L, Connolly ES Jr, Mayer SA, Young WL, Pile-Spellman J, et al. Complex intracranial aneurysms: combined operative and endovascular approaches. Neurosurgery. 1998; 43: 1304-1312. Ref.: https://goo.gl/8LZ1BA

7. Fandino J, Taussky $\mathrm{P}$, Marbacher $\mathrm{S}$, Muroi $\mathrm{C}$, Diepers $\mathrm{M}$, et al. The concept of a hybrid operating room: applications in cerebrovascular surgery. Acta Neurochir Suppl. 2013; 115: 113-117. Ref.: https://goo.gl/R2NvTJ

8. Murayama $\mathrm{Y}$, Arakawa $\mathrm{H}$, Ishibashi $\mathrm{T}$, Kawamura $\mathrm{D}$, Ebara $\mathrm{M}$, et al. Combined surgical and endovascular treatment of complex cerebrovascular diseases in the hybrid operating room. $J$ Neurointerv Surg. 2013; 1: 489-493. Ref.: https://goo.gl/hUCy4N

9. Piotin M, Blanc R. Balloons and stents in the endovascular treatment of cerebral aneurysms: vascular anatomy remodeled. Front Neurol. 2014; 5: 41-50. Ref.: https://goo.gl/zE96NL

10. Hanel RA, Spetzler RF. Surgical treatment of complex intracranial aneurysms. Neurosurgery. 2008; 62: 1289-1299. Ref.: https://goo.gl/uyhkqq

11. Andaluz N, Zuccarello $M$. Treatment strategies for complex intracranial aneurysms: review of a 12year experience university of cincinnati. Skull Base. 2011; 21: 233-242. Ref.: https://goo.gl/31KVJh

12. Chitale R, Chalouhi N, Theofanis T, Starke RM, Amenta P, et al. Treatment of ruptured intracranial aneurysms: comparison of stenting and balloon remodeling. Neurosurgery. 2013; 72: 953-959. Ref.: https://goo.gl/cNypTX

13. Raymond J, Guilbert F, Weill A, Georganos SA, Juravsky L, et al. Long-term angiographic recurrences after selective endovascular treatment of aneurysms with detachable coils. Stroke. 2003; 34: 13981403. Ref.: https://goo.gl/2KfkZC

14. Roach MR. A model study of why some intracranial aneurysms thrombose but others rupture. Stroke. 1978; 9: 583-587. Ref.: https://goo.gl/ma4BMe

15. Smith RL, Blick EF, Coalson J, Stein PD. Thrombus production by turbulence. J Appl Physiol. 1972; 32: 261-264. Ref.: https://goo.gl/WEG5pS

16. Guglielmi G, Vinuela F, Dion J, Duckwiler G. Electrothrombosis of saccular aneurysms via endovascular approach. Part 2: Preliminary clinical experience. J Neurosurg. 1991; 75: 8-14. Ref.: https://goo.gl/PGuXkD 
17. Moret J, Cognard C, Weill A, Castaings L, Rey A. Reconstruction technic in the treatment of wideneck intracranial aneurysms. Long-term angiographic and clinical results. Apropos of 56 cases. $J$ Neuroradiol. 1997; 24: 30-44. Ref.: https://goo.gl/ztpZ9X

18. Van Rooij WJ, Sluzewski M, Metz NH, Nijssen PC, Wijnalda D, et al. Carotid balloon occlusion for large and giant aneurysms: evaluation of a new test occlusion protocol. Neurosurgery. 2000; 47: 116-121. Ref.: https://goo.gl/43PyMZ

19. Shcheglov VI. Endovascular occlusion of saccular intracranial aneurysms: Results in 617 patients, 27th Annual Meeting of the American Society of Neuroradiology, Orlando, Florida, March 1989.

20. Fox AJ, Vinuela F, Pelz DM, Peerless SJ, Ferguson GG, et al. Use of detachable balloons for proximal artery occlusion in the treatment of unclippable cerebral aneurysms. J Neurosurg. 1987; 66: 40-46. Ref.: https://goo.gl/cmPQJj

21. Fiorella D, Albuquerque FC, Masaryk TJ, Rasmussen PA, McDougall CG. Balloon-in-stent technique for the constructive endovascular treatment of ultra wide-necked circumferential aneurysms. Neurosurgery. 2005; 57: 1218-1227. Ref.: https://goo.gl/nPiQ6q

22. Raymond J, Guilbert F, Roy D. Neck-bridge device for endovascular treatment of wide-neck bifurcation aneurysms: initial experience. Radiology. 2001; 221: 318-326. Ref.: https://goo.gl/agbEc5

23. Guglielmi G, Vinuela F, Sepetka I, Macellari V. Electrothrombosis of saccular aneurysms via endovascular approach. Part 1: Electrochemical basis, technique, and experimental results. J Neurosurg. 1991; 75: 1-7. Ref.: https://goo.gl/56A1g7

24. Kim M, Levy El, Meng H, Hopkins LN. Quantification of hemodynamic changes induced by virtual placement of multiple stents across a wide-necked basilar trunk aneurysm. Neurosurgery. 2007; 61 1305-1313. Ref.: https://goo.gl/sWd4hj 